\title{
A PRODUÇÃO DE CONHECIMENTO EM EDUCAÇÃO FÍSICA/CIÊNCIA DO ESPORTE - QUALIDADE X QUANTIDADE: PARA ONDE VAMOS?
}

\section{KNOWLEDGE PRODUCTION IN PHYSICAL EDUCATION/SPORT SCIENCE - QUALITY X QUANTITY: WHERE ARE WE GOING?}

\section{LA PRODUCCIÓN DE CONOCIMIENTO EN EDUCACIÓN FÍSICA/CIENCIA DEL DEPORTE - CUALIDAD x CANTIDAD: ¿ADÓNDE VAMOS?}

\section{Paulo Evaldo Fensterseifer ${ }^{1}$}

\begin{abstract}
Resumo: Este texto, recorrendo à argumentação científico-filosófica no que respeita ao problema da objetividade dos saberes, problematiza as pretensões de identificar com exatidão objetividades no campo das ciências, em particular das ciências humanas ou sociais. Pergunta-se pelo lugar da Educação Física neste debate, considerando a "virada culturalista", que põe em crise o modelo naturalista hegemônico na área. O texto aponta possíveis desdobramentos para a produção do conhecimento a partir da compreensão de que a Educação Física é uma construção históricocultural, apostando no diálogo entre os diferentes campos de produção do conhecimento, considerando, na geração de possíveis soluções, as dimensões políticas, epistêmicas e didáticopedagógicas.
\end{abstract}

Palavras-chave: Epistemologia. Objetividade. Ciência. Racionalidade.

\begin{abstract}
This text, using scientific-philosophical argument with regard to the issue of objectivity of knowledge, discusses the claims to identify with accuracy objectivity in the sciences, in particular human or social sciences. It wonders the place of physical education in this debate, considering the "culturalist turn" that brings into crisis the naturalist hegemonic model in the area. It points out possible consequences for knowledge production from the understanding that physical education is a historical and cultural construction, banking on dialogue between the different fields of knowledge production, considering, in the generation of possible solutions, the political, epistemic and didactic and pedagogical dimensions.
\end{abstract}

Keywords: Epistemology. Objectivity. Science. Rationality.

\footnotetext{
${ }^{1}$ Universidade Regional do Noroeste do Estado do Rio Grande do Sul (Unijuí). Ijuí, Rio Grande do Sul, Brasil.
} 
Resumen: El presente texto, recurriendo a la argumentación científico-filosófica respecto al problema de la objetividad de los saberes, problematiza la búsqueda por identificar con exactitud objetividades en el campo de las ciencias, en particular de las ciencias humanas o sociales. Se pregunta por el lugar de la Educación Física en esta discusión, considerando el "cambio culturalista", que pone en crisis el modelo naturalista hegemónico en el área. El texto apunta posibles desdoblamientos para la producción del conocimiento a partir de la comprensión de que la Educación Física es una construcción histórico-cultural, apostando en el diálogo entre los diferentes campos de producción del conocimiento, considerando, en la elaboración de posibles soluciones, las dimensiones políticas, epistémicas y didáctico-pedagógicas.

Palabras clave: Epistemología. Objetividad. Ciencia. Racionalidad.

A abordagem com a qual acredito poder contribuir para o debate acerca do tema expresso no título deste ensaio, valendo-me da expressão benjaminiana, é a de "escovar a contrapelo" os termos em questão. Em particular, evidencio o quanto esta problemática tem na base o tema da linguagem e seu esforço em enunciar o "ser" sem as imprecisões da linguagem ordinária, fugindo, portanto, do seu caráter interpretativo. Pode-se afirmar que as disputas em torno do conhecimento, com suas pretensões de objetividade, não é tanto contra "uma interpretação equivocada", mas contra a própria ideia de interpretação, ${ }^{2}$ posto que esta alcança, no máximo, aspectos parciais da realidade. O esforço da razão, com pretensões de universalidade, é superar o caráter perspectivo das interpretações. É nesta busca que concepções lógico-semânticas da linguagem, inspiradas na linguagem matemática, emergem como saídas promissoras. ${ }^{3}$

A transparência em relação ao problema do conhecimento é, em última instância, a busca pela supressão dos elementos controversos da condição humana, nunca resolvidos "de vez" e, para lembrar Nietzsche (1987), é uma ferida que não cicatriza nunca. Ruedell $(2016$, p. 85), no entanto, afirma que

Não faltaram, na História, sonhadores de uma comunicação direta e perfeita entre as consciências, sem a mediação de palavras e discursos ou outros meios, que sempre são deficientes; ao mesmo tempo transmitem uma mensagem e também a retém parcialmente, em virtude de sua opacidade.

A seriedade desta questão pode ser reconhecida em algo "não sério", como uma tirinha de Quino:

\footnotetext{
${ }^{2}$ Este debate encontra-se já nas divergências entre os sofistas e o Sócrates dos diálogos de Platão.

${ }^{3}$ Este movimento está na raiz do caráter instrumental que assumirá a linguagem em nossa tradição, e que será abalada com o giro linguístico. Não devemos ignorar que essa "guinada" contemporânea possui dívidas com o pensamento sofista, marginalizado pela hegemonia platônica.
} 
Figura 1 - O Dilema de Mafalda
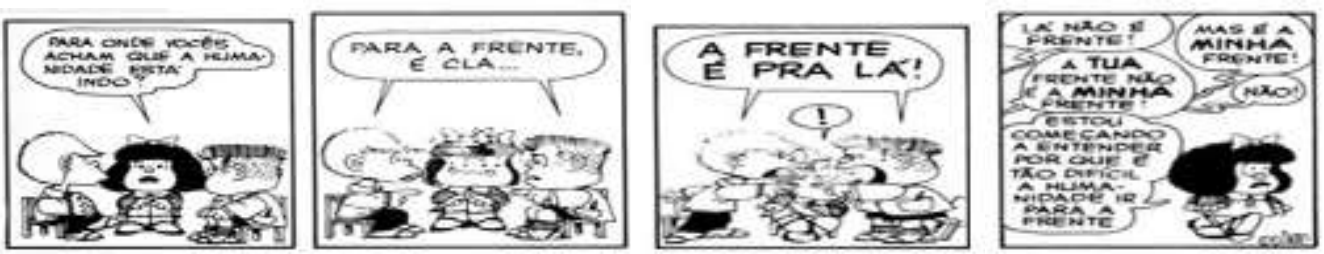

Fonte: QUINO, 2015. ${ }^{4}$

Não seria exagero afirmar que na conclusão de Mafalda reside parte significativa dos problemas da sociabilidade humana (eu e os outros). Algo que a experiência grega, em sua invenção democrática, reconhecia como um problema da doxa (opinião), portanto, dos cidadãos da pólis, que, a cada vez, necessitavam deliberar sobre temas do mundo comum. A posição segue explícita na afirmação de Protágoras de Abdera: "O homem (de cada vez) é a medida de todas as coisas [...], das que estão presentes pelo fato de aí assim serem como aí estão [...], daquelas, porém, a quem fica negado estarem presentes pelo fato de que não estarem aí" (HEIDEGGER, 2005, p. 222).

É importante distinguir que o "homem de Protágoras", conforme a primeira parte da frase, não é o sujeito cartesiano, com suas pretensões de uma "subjetividade universal" (espécie de franquia da mente divina). A segunda parte, porém, pode ser exemplificada pelo universo da ação, inviabilizando, em relação a este, qualquer possibilidade de deliberar acerca de questões futuras.

Platão, crítico da experiência democrática que condenou à morte o seu mestre Sócrates, não aceitou que problema tão relevante como o futuro da pólis fosse alvo da deliberação do conjunto dos cidadãos. Coloca-se, então, a proposição platônica de uma pólis regida por uma epistéme. Isto é expresso no Livro VII da República, no conhecido "Mito (alegoria) da Caverna", como representado a seguir:

\footnotetext{
${ }^{4}$ Quino (Joaquín Salvador Lavado Tejón), humorista argentino criador da personagem Mafalda. Disponível em: http://clubedamafalda.blogspot.com.br/. Acesso em: 21 set. 2015.
} 
Figura 2 - Mito da Caverna

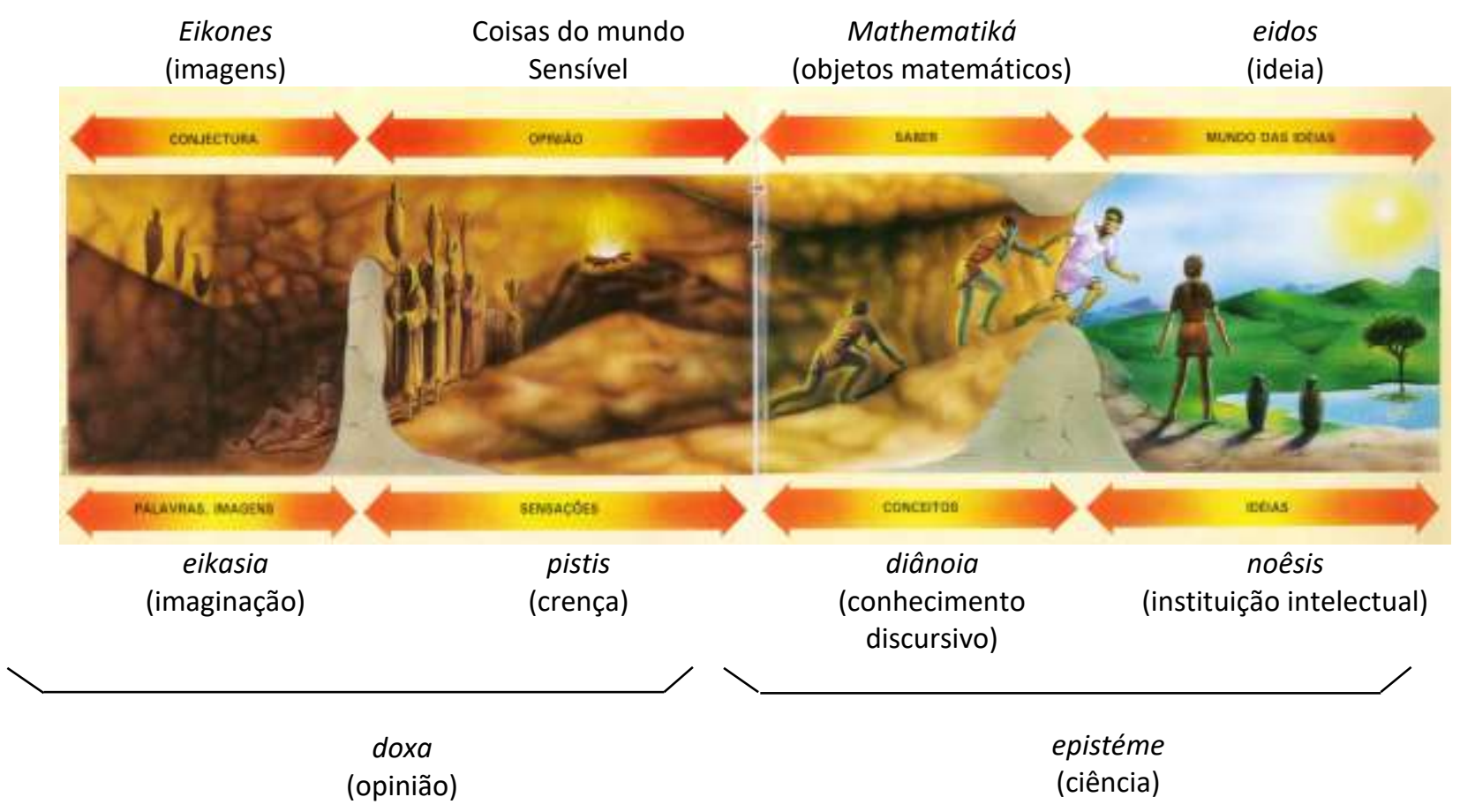

Fonte: HISTÓRIA DO PENSAMENTO, 1987, p. 53-75.

Nesta proposição platônica já se percebe o lugar da matemática no pensamento ocidental, em seu vínculo com as questões políticas e no enlace com a ética e com a educação (temas inseparáveis para os gregos).

Uma das principais lições deste mito vincula-se ao esforço para chegar ao conhecimento verdadeiro, que é de natureza conceitual, o mais próximo possível das "ideias verdadeiras", as quais compõem o "mundo verdadeiro". A pretensão de verdade é destacada à exaustão e explicitamente vinculada ao mundo das ideias (não dos sentidos), que seriam obtidas por um pensamento sem linguagem. Acerca desta concepção de linguagem de Platão, afirma Oliveira (1996, p. 22):

As palavras, enquanto humanas, são passíveis de erro. Frente a isso Platão entende que deve haver uma forma de conhecer que permite o julgamento entre as palavras verdadeiras e as palavras falsas, ou, que deve ser possível conhecer sem os nomes. Nessa linha ele conclui que o verdadeiro conhecimento ocorre sem palavras, sem a mediação linguística, sendo que para o seu conhecimento temos a contemplação das ideias, o puro pensar, o diálogo sem palavras, da alma consigo mesmo.

Platão estabelece, no entender de Oliveira (1996, p. 22), “a distinção radical entre pensamento e linguagem, reduzindo esta a uma expressão secundária, de mero sinal, capaz de expressar o que se elabora fora dela". Logo, o desafio é conceber um sistema ideal de sinais (talvez matemáticos), "que permita ao homem um domínio perfeito do mundo objetivo, 
independentemente das contingências, imperfeições e limitações das línguas naturais. Com isso estaria realizada, de modo supremo, a função instrumentalista da linguagem". Diante disso, poderse-ia perguntar: Não continua sendo esse o sonho de certo tipo de ciência?

Este ideal foi retomado posteriormente pelo "lullismo", cuja corrente de pensamento seguia os objetivos de Ramón Lull (RAIMUNDO LULLUS, 1235-1315), que desejava conduzir todo o conhecimento humano a um conceito unívoco, expresso em algo como um "alfabeto de símbolos", operado matematicamente (OLIVEIRA, 1996, p. 23, nota 10).

$\mathrm{Na}$ Modernidade, Descartes - um grande matemático, pai fundador do pensamento moderno (que já nasceu com o DNA da matemática) - deu um novo e decisivo alento para este projeto. Para ele,

[...] a Aritmética e a Geometria são muito mais certas do que as outras disciplinas: é que são as únicas a versar sobre um objeto tão puro e tão simples que elas não têm de fazer, em absoluto, nenhuma suposição que a experiência possa deixar duvidosa e são inteiramente compostas de conseqüências que devem ser deduzidas racionalmente. Portanto, elas são as mais fáceis e as mais claras de todas, e têm um objeto tal como o exigimos, pois que, salvo inadvertência, mal parece possível a um ser humano nelas enganar-se (1999, p. 9).

Explicita-se, aqui, a noção de objeto ideal das ciências, ou seja, aquele que pode ser aprendido com exatidão. Uma vez realizada esta tarefa, o próprio comportamento futuro (primeiro da matéria e depois da sociedade) pode ser deslumbrado, em sua pretensa linearidade, com precisão matemática. Logo, o "por-vir" nada tem a nos ensinar, e o plano da ação humana livre vira fabricação, engendramento do que previamente a razão produziu.

Esta forma de proceder logo passa a ser critério ontológico, como afirma Figueiredo (1995, p. 138): “[...] ser é ser representável, é ser objetivável numa representação e tudo aquilo que escape ou se furte a uma representação clara e distinta estaria assim destituída de estatuto ontológico ou, pelo menos, teria sua realidade posta em suspeição".

Pode-se compreender, então, porque esse pensamento instiga em nós o mal-estar com as incertezas, com as "zonas cinzentas", com o risco e com o erro, e, por outro lado, a razão do fascínio humano pela exatidão, o absoluto, o pensamento "sem arestas", "preto no branco", enfim, pelas simplificações de toda ordem; ${ }^{5}$ algo que se consegue quando instrumentalizamos a linguagem e a submetemos a uma perspectiva meramente funcional; base do que Horkheimer (1976) vai denominar a "vertigem da matemática".

\footnotetext{
5 Isso, quem sabe, ajude a entender a projeção de líderes que nos poupam da necessidade de lidar com a complexidade e apresentam traduções, mediações, daquilo que não entendemos ou não queremos fazer o esforço de entender.
} 
Assim que um pensamento ou uma palavra se torna um instrumento, podemonos dispensar de "pensar" realmente isso, isto é, de examinar detidamente os atos lógicos envolvidos na formulação verbal desse pensamento ou palavra. Como já se tem afirmado, com frequência e corretamente, a vantagem da matemática o modelo de todo pensamento neopositivista - reside justamente nessa economia intelectual (HORKHEIMER, 1976, p. 31).

Este frankfurtiano alerta para o processo de "formalização da razão", o qual permite tornar complexas questões intelectuais em operações lógicas, o que pode ser adequado para a mecanização que potencializa a indústria, mas torna-se fetiche quando, pela não compreensão da sua natureza, é universalizada, reduzindo a ciência à "classificação de fatos e cálculo de

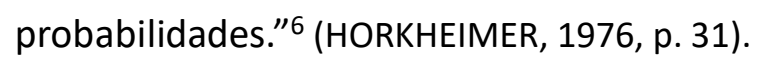

Retomando o fio da tradição do pensamento "matematizante", outra figura de destaque nesta trilha do cartesianismo, igualmente matemático, é Leibniz, o qual sugere, segundo Oliveira (1996), a possibilidade de transformar o raciocínio em uma espécie de cálculo, tendo como télos a aplicação dos métodos matemáticos ao conjunto do conhecimento humano. Para ele, a maneira usual de argumentar dificilmente permite chegar a um acordo, por isso propõe que os raciocínios sejam transformados em cálculos, obtendo conclusões como se fossem resultados aritméticos. Neste caso, a linguagem, transformada em simbólica matemática, "seria o instrumento perfeito da subjetividade para o domínio do mundo" (OLIVEIRA, 1996, p. 23); seguramente uma solução tentadora para os personagens de Quino (nós humanos).

Nessa mesma lógica (e é lógica matemática) coloca-se o esforço de Galileu Galilei, expresso nesta conhecida passagem:

A filosofia (ciência) está escrita neste grandíssimo livro, que nos está continuamente aberto diante dos olhos (quero dizer universo), mas não se pode entender sem antes aprender a entender a língua e entender os caracteres em que está escrito. Ele é escrito em língua matemática, e os caracteres são triângulos, círculos e outras figuras geométricas (apud ROSSI, 1992, p. 203-204).

Esta afirmação é fundamental para a autonomização do campo científico da tutela religiosa, sustentada, como não poderia ser diferente naquele momento, por argumentos teológicos, afirmando a dupla linguagem, a divina, dos escritos sagrados, e a da natureza, das ciências, havendo, para cada uma delas, a necessidade de dominar os caracteres com os quais foram escritas (ROSSI, 1992). Logo, nos seminários e conventos se deveria estudar Aramaico,

\footnotetext{
${ }^{6}$ Olgária Matos (2010) identifica neste entendimento a tendência das pesquisas tecnicistas que dispensam o mundo cultural e histórico. Com isto, "nada mais suscita nos estudantes a admiração ou a perplexidade [...] Trata-se de uma educação que produz uma 'cultura da incuriosidade', que nada surpreende e imune ao maravilhamento." (ZAWADIZKI apud MATOS, 2010, p. 161).
} 
Hebraico, Grego e Latim, enquanto nas universidades, a matemática, e as ciências que possam nela se inspirar (buscando aplicação a setores da realidade).

Podemos reconhecer, neste apelo de Descartes e Galileu a uma razão matemática, ecos do fascínio parmenídico e platônico pelo imutável, pelo eterno, que não se subjuga ao tempo e ao espaço em que a vida transcorre. Estes pilares da ciência moderna da natureza constituem o que Kant (1987) denominou de "razão pura", a qual prima por não se confundir com as coisas mundanas, buscando um tal grau de separação que permita seguir apenas as suas leis internas, as quais, no entender de Kujawski (1991, p. 164), têm na matemática seu produto exemplar ${ }^{7}$. Este autor, porém, afirma que

A razão pura é a melhor possível para apreender a natureza e equacioná-la matematicamente, mas não serve para entender a vida humana, nem as ciências do humano, a história, a sociologia, a antropologia, a política. Não serve para constituir a minha vida, em sua temporalidade, em sua individualidade, em seu dinamismo e em sua variação. Não há equação matemática que sintetize a história de Roma, ou a biografia de Napoleão, nem mesmo a do mais pobre e humilde dos mortais (KUJAWSKI, 1991, p. 164).

Fica evidente, então, que a ancoragem que a ciência moderna busca na matemática é o modo encontrado para resolver o problema da verdade sem incorrer, por um lado, na "tentação metafísica"8 e, por outro, no "círculo vicioso da hermenêutica". ${ }^{9}$ O saber científico matematizante quer prescindir do saber narrativo e de suas demandas de interpretação (sempre imprecisas); mas, em um olhar retrospectivo, podemos identificar o quanto este intento se depara com uma "nova metafísica"; não mais teológica, alicerçada em um transcendente, mas em um sujeito transcendental que passa à condição de fundamento ontológico, epistemológico e ético.

O sujeito torna-se fundamento ontológico ao condicionar a existência da realidade das coisas à sua capacidade de representá-las; transforma-se em fundamento epistemológico ao destituir a autoridade e a tradição como fonte de legitimidade do conhecimento, substituindo-as pela certeza subjetiva como fonte desta legitimação; e torna-se fundamento ético ao destituir do lugar de obviedade os padrões tradicionais e coletivos, passando a definir autonomamente as suas regras de ação. Como entende Figueiredo (1995), tamanha tarefa demanda um sujeito completamente autônomo, autotransparente e autodeterminado, senhor absoluto da própria

\footnotetext{
${ }^{7}$ Kujawski, recorrendo a J. Marías Ortega, destaca que a razão pura não se confunde com o entendimento em si, "mas certa maneira extremada de este funcionar." (KUJAWSKI, 1991, p. 164).

${ }^{8}$ Chamo aqui "tentação metafísica" o esforço de constituir um ponto de vista a-histórico, situado fora da linguagem, e que, por isso, possa corrigir a intransparência da linguagem. Neste esforço ignora-se o caráter propositivo e perspectivo das verdades humanas, as quais têm endereço e fazem aniversário.

${ }^{9}$ Reconhecimento do caráter interpretativo de todo enunciado humano com pretensões de verdade e que só mais tarde, pós giro linguístico, terá reconhecido seu caráter "virtuoso".
} 
vontade. Este projeto ontológico, epistemológico e ético da modernidade, preconiza o "silêncio do corpo", reduzindo a subjetividade à consciência, dever e vontade, e a vida tornar-se um mero exercício de geometria (FIGUEIREDO, 1995, p. 30-32). Esta subjetividade, entende Fensterseifer (2001, p. 55-56),

[...] só pode ser construída a partir de um processo de desnaturalização do homem, o que, à medida em que o corpo é tomado como parte da natureza, vai significar um processo de "desencarnação", ou "desincorporação". O homem moderno coloca-se, assim, acima da natureza, livre dos seus desígnios, como livre está dos desígnios de Deus. É ele agora o ser onipotente, fundamento de toda verdade e valor, bem como do próprio mundo, tendo pela frente uma liberdade infinita.

O saber que a modernidade almeja, que irá constituir a solidez para todo o edifício da ciência moderna, evita recorrer ao teológico ("laçar a torre da igreja"), sem se perder no atoleiro das interpretações geradas por uma linguagem babélica. Daí a crítica de Lyotard $(1988$, p. 53) à origem destas pretensões:

$O$ fato é que o discurso platônico que inaugura a ciência não é científico, e isto à medida que pretende legitimá-la. O saber científico não pode saber e fazer saber que ele é o verdadeiro saber sem recorrer a outro saber, o relato, que é para ele o não saber, sem o que é obrigado a se pressupor a si mesmo e cai assim no que ele condena, a petição de princípio, o preconceito. Mas não cairia também nisto valendo-se do relato?

O problema coloca-se, também, contemporaneamente ao neopositivismo, pois este, ao afirmar que somente pode ser tomado como verdadeiro aquilo que passa pelo crivo da observação e da experimentação, ignora que esta petição de princípio não se submete ao próprio critério que o princípio enuncia (o que teria levado um dos seus propositores ao suicídio).

$\mathrm{Na}$ crítica, talvez a mais radical a estas pretensões da ciência moderna, situa-se o pensamento de Heidegger (2005), segundo o qual o esforço matematizante da ciência moderna transforma-se em "leito de Procusto", em que deve "deitar-se toda realidade", pretensão objetificadora que ignora sua condição interpretante. Logo, suas elaborações epistêmicas com pretensões onto-teo-lógicas recaem na metafísica ao absolutizar seus critérios.

Fugindo da "torre da igreja", os materialismos buscam o chão firme do "real", o qual, ao apresentar-se como "transparente", livre de interpretações ideológicas, assume uma condição metafísica pré-kantiana. Novamente a epistéme cede à tentação ontológica, tal como revela esta passagem de Heidegger (1988, p. 273) em Ser e Tempo: “[...] a pre-sença (dasein) enquanto ser no mundo, possui a tendência de primeiro sepultar epistemologicamente o 'mundo exterior' em um nada negativo para então permitir que ele ressuscite mediante provas"; "provas" obviamente de 
caráter matemático, afinal "foi reservado o matemático como nome para o que é conforme aos números" (HEIDEGGER, 2005, p. 195). Segue o autor:

O rigor da ciência matemática da natureza é a exatidão. Todos os processos devem aqui ser determinados previamente como grandezas de movimento espaço-temporal, caso quiserem de algum modo chegar à representação enquanto fenômeno da natureza. Tal determinação efetua-se pela medição com a ajuda do número e do cálculo. A pesquisa matemática da natureza entretanto, não é exata pelo fato de calcular com exatidão, mas ela tem de calcular assim, porque a ligação ao seu setor de objetos tem o caráter da exatidão (HEIDEGGER, 2005, p. 195-196).

Como ficam, então, outros campos da ciência, em especial se for levada a sério a noção de que os seres humanos se aproximam mais dos contos do que das contas (SAVATER, 1998)? No entender de Heidegger (2005, p. 196), na contramão desta lógica matematizante

[...] todas as ciências do espírito, inclusive todas as ciências sobre o vivo, necessariamente têm de ser inexatas a fim de, precisamente, permanecerem rigorosas. Na verdade pode-se conceber também o vivo como uma grandeza de movimento espaço-temporal, mas então não mais se capta o vivo.

Esta é, quem sabe, a tese central para o debate ora proposto, cujos desdobramentos revelam os modos de tratar seus temas, tais como corpo, movimento, saúde, práticas corporais... Ademais, claro está que "A inexatidão das ciências históricas do espírito não é uma falta, mas o cumprimento de uma exigência essencial para esse modo de investigação" (HEIDEGGER, 2005, p. 196).

Diante disso, é possível perguntar: E a Educação Física, como se situa neste movimento? O que significou a "virada culturalista" que colocou, ou buscou colocar, o modelo naturalista hegemônico em crise? Que desdobramentos põem-se a partir da compreensão de que a Educação Física é uma construção histórico-cultural? Qual a relação da linguagem dos conhecimentos com os próprios objetos conhecidos? É possível uma tradutibilidade sem perdas? É possível uma linguagem quantificadora para o conjunto dos fenômenos abarcados pela área? Qual o caráter dos ganhos? Qual o prejuízo? ${ }^{10}$

Entre os pressupostos para se prosseguir nesse caminho está a realidade humana, a qual não se dá alheia a uma produção de sentido que lhe é constitutiva. Rolim (2011, p. 16) muito bem expressa essa realidade:

Os sentidos das coisas, não os encontramos nelas. O mundo, em si mesmo, é a realidade do sem sentido. O sentido é aquilo que nós emprestamos às coisas. Quando vemos algo, quando temos notícia de algo, temos a ilusão de que este

\footnotetext{
${ }^{10}$ Estas questões não são aqui listadas para serem enfrentadas no âmbito deste texto (seria demasiada pretensão), mas para indicar a insuficiência das perspectivas quantitativas para tratá-las com o rigor exigido, dada a complexidade que as acompanha.
} 
algo nos revela o que é. Mas a realidade-do-que-é aguarda nossa intervenção como observador, como leitor, como ouvinte. Por óbvio, as coisas existem independentemente de nossa apreensão, mas o sentido delas corresponde sempre a uma atribuição do sujeito.

A isso se poderia agregar: sujeitos forjados no interior de uma linguagem portadora de sentidos. Palmer ([1997], p. 230), por sua vez, afirma: “[...] O sujeito compreende através do mundo partilhado da compreensão, já dado na e pela linguagem que utiliza, bem como do posicionamento histórico em que a sua compreensão se coloca".

Inspirado neste modo de relação com a produção do conhecimento, apresento, na sequência, uma série de "teses" que podem ajudar a pensar em como são enfrentadas as questões epistemológicas da área:

- ao selecionar/delimitar um fenômeno, afirma-se o que se identifica como Educação Física e, ao descrevê-lo, reitera-se o seu caráter. Logo, o real referido é uma construção;

- a ciência cria o objeto ao delimitar (determinatio ist negatio, lembrando expressão spinoziana);

- "[...] esse algo no mundo sobre o qual se quer construir um discurso é já algo do mundo da cultura, é algo construído socialmente" (SILVA, 1999, p. 45);

- se, conforme Foucault (1995), os enunciados epistêmicos são político-ideológicos, logo não existe observação livre de pressupostos. Toda observação já está impregnada de teoria;

- "[...] deve-se reconhecer que o próprio objeto de conhecimento científico não é apreendido diretamente da observação, mas do contrário, pela construção teórica realizada pelo observador" (PALMA, 2001, p. 37);

- os fatos científicos são produto da ciência.

A compreensão dessas questões permite perguntar se este modo de apreensão do real (ciência) dá conta de outras questões, como conteúdos curriculares, processos pedagógicos, objetivos de ensino, qualidade de vida, cultura corporal de movimento... Ou podemos ir mais longe, tal como faz Feyerabend (1977), quando recomenda "que a ciência seja posta em seu lugar, como forma interessante, mas de modo algum exclusiva, do conhecimento, que apresenta vantagens e desvantagens." (p. 340).

Depreende-se daí que o universo de questões que configura um campo do saber (ciência?), mesmo considerando a mobilidade e a instabilidade de suas fronteiras, ou exatamente por isso, não pode ter as dificuldades que lhe são inerentes reduzidas a problemas científicos, muito menos de ordem e medidas matemáticas. 
Obviamente que poderíamos agir como a raposa que declara verdes as uvas que não alcança. Movimento similar ao que percebe Coli (2010), quando, diante do mistério, negamos o que não somos capazes de explicar, enquanto as artes nos ensinam a conviver com ele. Exemplifica o autor supracitado:

[...] muitos pensamentos suficientes e autoritários decidiram terminar, de uma vez por todas, com a ideia insuportável de gênio. Não podemos explicá-lo, portanto, ele não existe. Fruto de um obscurantismo perverso ou de um idealismo reacionário, além de não existir, ele deve ser insultado (2010, p. 284).

Este traço de negação, afirma Coli (2010), não se fazia presente entre os antigos, os renascentistas, os românticos, os quais, de diferentes maneiras, reconheciam o quanto de inexplicável está na base da criação artística e, podemos acrescentar, persiste no esforço hermenêutico que acompanha a "vida" destas criações.

"Genialidade e mistério" acendem a luz vermelha das causalidades explicativas que a tudo querem digerir sem deixar "restos", revelando os limites de uma forma de racionalidade que não reconhece as "trevas" como constitutivas da condição humana. Coli identifica nos românticos a sensibilidade para estes aspectos, tal como segue nesta passagem:

Os românticos foram direto ao cerne. Deram-nos a experiência das trevas, do sem destino, do sem sinal. Mostraram-nos que todos os sinais são falsos, não em nome de um sentido superior, mas porque não há sentidos. Lançaram-nos na angústia do mistério, onde certas vozes falam mais sabiamente que outras: as da loucura, as das crianças, as da mulher, as do povo, as do demônio, todos esses seres que não foram iluminados pela razão, mas que sabem exprimir as falas das trevas $^{11}$ (p. 284).

As práticas analíticas, baseadas em cadeias causais, necessitam, afirma o autor, abolir todo acaso presente no sem sentido das ações. Para esta forma de análise, o "incompreensível é absurdo", e se pergunta: "Que mecanismos psicológicos, que situações sociais, históricas, econômicas, políticas dão conta de tais quimeras?" Ao que a posição dos românticos é: "eles não dão conta." (COLI, 2010, p. 285)

Antes que se renda graças ao irracionalismo e se dispense o esforço racional, Coli (2010) alerta para que não simplifiquemos a questão opondo o racional a aquilo que está fora da razão, postura que ele identifica com a ortodoxa positividade lógica, para a qual "o irracional é o não ser da razão", inimigo do reino "harmonioso dos universais". A conclusão do autor é outra, tal como podemos ler nesta esclarecedora e instigante passagem:

\footnotetext{
${ }^{11}$ Coli (2010, p. 285) exemplifica os limites desta lógica racional na incapacidade da sociedade europeia em acolher a ópera de Verdi denominada /l Trovatore, na qual as paixões se sobrepõe às razões.
} 
Descobrimos apenas que se trata de não razão, isto é, de um outro domínio, pelo qual podemos ser levados a perceber o mundo e os seres, a uma sabedoria que não cabe nas equações. Atinamos que os caminhos emocionais, intuitivos, são modos também de conhecimento, mais profundos até, embora impronunciáveis, ou tão pouco, ou de outro modo. Poderíamos chegar ao princípio de uma razão dilatada, uma razão que desconfiasse dos seus próprios silogismos, e que aprendesse a respeitar, se não como superiores, pelo menos como iguais, essas outras sendas de saber (COLI, 2010, p. 285, grifos meus).

No enfrentamento destas questões, indicadas por Coli (2010), não parece pertinente seguir o projeto cartesiano do uso estrito da matemática "[...] para elaborar o discurso no interior do qual seríamos capazes, de modo seguro e infalível, de classificar os conteúdos, listar as dificuldades, localizar o que não é passível de conhecimento e encontrar as verdades em seus devidos lugares - sem distinção de gênero ou domínio" (LEBRUN, 2006, p. 132). A proposição cartesiana é de "construir o discurso homogêneo que unificará a produção e o encadeamento de todos os enunciados ditos 'científicos'." (p. 132). Nesse projeto, as ciências particulares, nas palavras do próprio Descartes (apud LEBRUN, 2006, p. 132), "nada mais são que a humana sabedoria que permanece idêntica a si mesma, por mais diversos que sejam os objetos aos quais elas se aplicam [...]."

Este "monopólio da racionalidade" não reservaria lugar nenhum para as "racionalidades regionais". Lebrun (2006, p. 132) questiona: "Ora, de que função pode encarregar-se uma epistemologia em que ciência alguma é considerada produtora de sua racionalidade?"12

Retomando uma conhecida expressão de Matisse, "Exatidão não é verdade" (cito de memória), podemos concluir que exatidão somente é critério de verdade, sinônimo de rigor, para quem embarcou no "jogo dos números", e desincumbiu-se das complexidades da natureza e do mundo humano. A exatidão, nestes termos, já não opera nem mesmo nos esforços da modelagem matemática ou da física não teórica, muito menos nos fenômenos da vida e nas complexidades humanas, sejam sociais ou individuais. Essa inflexão entre um a priori asséptico e o atoleiro da existência, encontra uma forma magistral em uma passagem de McEwan (2011, p. 9),

[...] Enquanto ainda convergíamos sem fazer contato, nos encontrávamos num estado de graça matemático. Demoro-me na contemplação de nossas posições, das distâncias e dos pontos cardeais porque, no que tange aos conhecimentos que vieram depois, essa foi a última vez que entendi alguma coisa claramente.

\footnotetext{
12 Lebrun (2006, p. 135) lembra que também Augusto Comte afirma que a matemática detém a chave "do modo universal de raciocinar aplicável a qualquer possível objeto do espírito humano".
} 
Essa pretensão de exatidão que acompanha o conhecimento humano foi alvo da crítica nietzschiana em pleno século 19 , no apogeu do otimismo acerca das potencialidades da racionalidade humana. Nietzsche $(1987$, p. 31) escreveu naquele momento que:

Em algum remoto rincão do universo cintilante que se derrama em um sem número de sistemas solares, havia uma vez um astro, em que animais inteligentes inventaram o conhecimento. Foi o minuto mais soberbo e mais mentiroso da "história universal": mas também foi somente um minuto. Passados poucos fôlegos da natureza congelou-se o astro, e os animais inteligentes tiveram de morrer.

Inspirado nesta passagem, posso afirmar que, em algum lugar, os humanos inventaram a matemática. Foi um dos momentos mais criativos destes seres. Em seguida, encantados com seu invento, tentaram explicar todas as coisas, vivas ou não vivas, presentes e passadas, a partir dessa nova linguagem, agora considerada "a linguagem". Suas verdades passaram a desconhecer tempo, espaço e autoria. Foi a decisão mais estúpida desses seres; não sem consequências, tal como alerta Rosa (1973): “A lógica [...] é a força com a qual o homem algum dia haverá de se matar. Apenas superando a lógica [matemática] é que se pode pensar com justiça".

As abstrações matemáticas/geométricas, tão fundamentais para o caráter de exatidão do conhecimento científico, desapareceriam por completo à medida que estes seres de linguagem que as criaram sucumbissem. Não reconhecer isso é o criador não se reconhecer na criatura; em outras palavras, é metafísica. Não é gratuito que este modelo civilizatório tenha na filosofia de Platão um de seus pilares, o qual chegou ao mundo das ideias pelas abstrações matemáticas. Estes entes encantam e cegam pelas suas verdades indubitáveis, prestando-se para forjarmos a crença em verdades não submetidas à historicidade, não corrosíveis pelo tempo e livres de qualquer contexto; mais uma vez, substrato de toda metafísica.

Na tentativa de nos afastar desta "tentação metafísica", necessitaríamos preservar algo como um "reflexividade sensível", e, tal como os românticos, apontar para o "irracionalismo da racionalidade", a qual, "tomada de uma embriaguez triunfante, enlouquece" (COLI, 2010, p. 286). Para este autor, não são raro os momentos em que a ciência, tomada pelo pecado do orgulho, em um raciocínio autossuficiente, produz efeitos desastrosos sobre o mundo. E conclui: "A hybris da razão faz aflorar o germe irracional ali escondido." (COLI, 2010, p. 286).

Segundo Coli $(2010,286)$, os românticos sabiam que a irracionalidade é criação da razão, a qual estabelece a fronteira que, poderíamos acrescentar, permite sua autocertificação. $O$ autor destaca uma série de outros "saberes dos românticos", tais como: 
Mostraram o quanto havia de obscurantista nas certezas e nas verdades. Aprenderam, e ensinaram, a lidar como o incerto, com o duvidoso, de que o mundo é feito. Revelaram a solidão e o abandono de que os homens são feitos. Praticaram uma sensibilidade inconformada, em desacordo com as regras, rebeldes diante das harmonias que se dispunham como eternas e reais, e que eles sabiam falsas. Centraram essas revoltas no indivíduo, pois toda forma de conforto solidário e coletivo instaura a força das conviç̧ões incontestes. Extremaram, certo, as convicções pessoais - mas só quando elas determinavam conflitos e contradições. Foram cavaleiros solitários, pois não acreditavam na universalidade das escolhas (COLI, 2010, p. 286).

Coerente com a postura que "não dispensa a razão", sabendo reconhecer que algo pode ser insuficiente mas, nem por isso, desnecessário, Coli conclui:

A razão oferece etapas a serem cumpridas para seu aprendizado. Com método, não há por que desesperarmos de atingir o universal. Entretanto, como descobrirmos os caminhos do mistério? Não há método para tanto. No que precedeu, constatamos sensibilidades, intuições, emoções, atitudes, comportamentos, estesias e quase uma ética. Tudo isso não constitui momentos de um aprendizado progressivo e organizado (COLI, 2010, p. 286).

Uma ciência, pautada por estes "alertas", demanda outra(s) epistemologia(s). O epistemólogo de hoje, afirma Lebrun (2006, p. 138), "só pode visar à cientificidade sob a condição prévia de destruir esses monstros identitários forjados pelos manuais e pela vulgarização: ‘a ciência', 'uma ciência'...”, e acrescenta:

A catástrofe aconteceu, a episteme una morreu, mas seu luto quase não pesa, embora não andemos por aí alardeando niilismo. No lugar vazio deixado pela "humana sabedoria", eis que nascem os "gaios saberes", as epistemologias saberes ainda adolescentes, agressivos, insolentes, subversivos, que desrespeitam a cientificidade de direito divino por respeitarem mais a ciência como trabalho e como documento. A epistemologia está na moda: é um sinal de saúde. É a indicação de que as ciências se tornam divertidas quando as consideramos como jogos dos quais é preciso encontrar as regras e de que se tornam interessantes apenas quando não mais cremos na Verdade (p. 144).

Postas estas questões, voltemos ao "Dilema de Mafalda": Para onde vamos? Se, tal como os personagens de Quino, precisamos nos entender acerca disso, e se a saída platônica, ou qualquer outra pretensão de epistéme universal, muito menos do social, não nos fascina mais, devemos buscar o diálogo entre os diferentes campos de produção do conhecimento, seguros de que nenhum deles guarda "a" Verdade; esta, com "V" maiúsculo, alheia ao tempo e ao espaço, somente seria atingível por um Deus transcendente que não faça aniversário.

Diante desse quadro, algumas dimensões importam na produção de possíveis soluções, sempre provisórias, tais como: 
a) Dimensão política: é o reconhecimento de que a liberdade acadêmica que usufruímos (que permite pensar o próprio sentido da universidade e da pesquisa como lugar da "crítica sem teto") é uma prerrogativa das sociedades democrático-republicanas.

b) Dimensão epistêmica: é o reconhecimento do caráter proposicional dos saberes que produzimos e ensinamos, o que não nos possibilita falar de verdades absolutas, embora nos permita reconhecer a objetividade das suas verdades.

c) Dimensão didático-pedagógica: é o reconhecimento de que não há aprendizagem sem o comparecimento dos sujeitos do processo educacional, os quais são potencializados pelas duas prerrogativas anteriores.

Mais uma vez, então, perguntamos: Para onde vamos? Continuamos sem saber, porém, tal como Aristóteles, que diferentemente de Platão reconhecia que o campo ético-político (saber phronético) não se pauta pela epistéme (GADAMER, 1998), que não se espera uma solução epistêmica para os problemas que aí estão, mas, também conforme Aristóteles, não se pode ignorar a existência de uma relação entre estas duas dimensões. O campo da ação, no qual se responde à questão posta, necessita desse discernimento para não virar mera "fabricação".

Espero, com este ensaio, ter produzido alguma luz, mesmo que bruxuleante, acerca da complexidade do tema, passo que considero importante para não empobrecermos o quadro de alternativas possíveis de serem produzidas. Destaco, também, que não alimento pretensões maiores do que essa, dado que a deliberação não pode prescindir dos sujeitos envolvidos nas tomadas de decisão. O contrário seria ceder à tentação de uma racionalidade instrumental que confunde a condição de autor com a de ator. Esta não é, de fato, a pretensão deste ensaio, o que espero ter ficado claro ao longo do texto.

Enfim, que cada um, com as metodologias mais diversas, produza conhecimentos com pretensões de objetividade, não metafísicas. A razoabilidade é tarefa de toda comunidade científica e não científica, tendo presente que em suas produções estão respondendo à interrogação "para onde vamos?"; e, não de menor importância, coincidindo acerca do Dilema de Mafalda: "Por que é tão difícil a humanidade ir para a frente."

\section{REFERÊNCIAS}

COLI, Jorge. Mistérios de um mundo sem mistérios. In: NOVAES, Adauto (org.). Mutações: a experiência do pensamento. São Paulo: Edições Sesc SP, 2010. 
DESCARTES, René. Regras para a orientação do espírito. Tradução de Maria Ermantina Galvão. São Paulo: Martins Fontes, 1999.

FENSTERSEIFER, Paulo Evaldo. A educação física na crise da modernidade. Ijuí: Editora Unijuí, 2001.

FEYERABEND, Paul Karl. Contra o método. Trad. Octanny S. da Mata Rio de Janeiro: Francisco Alves, 1977.

FIGUEIREDO, Luís Cláudio. Modos de subjetivação no Brasil e outros escritos. São Paulo: Escuta; Educ, 1995.

FOUCAULT, Michel. Arqueologia do saber. Tradução de Luiz Felipe Baeta Neves Rio de Janeiro: Forense Universitária, 1995.

GADAMER, Hans-Georg. O problema da consciência histórica. Tradução de Paulo Cesar Duque Estrada. Rio de Janeiro: Fundação Getúlio Vargas, 1998.

HEIDEGGER, Martin. Ser e tempo. Tradução de Márcia de Sá Cavalcanti. Petrópolis, RJ: Vozes, 1988. Parte I.

HEIDEGGER, Martin. A época da imagem do mundo. Tradução de Paulo Rudi Schneider. In: SCHNEIDER, P. R. O outro pensar: sobre que significa pensar? e A época da imagem do mundo, de Heidegger. ljuí: Editora Unijuí, 2005.

HISTÓRIA DO PENSAMENTO: das origens à Idade Média. São Paulo: Nova Cultural, 1987. V. 1.

HORKHEIMER, Max. Eclipse da razão. Tradução de Sebastião Uchoa Leite. Rio de Janeiro: Editorial Labor do Brasil, 1976.

KANT, Immanuel. Crítica da razão pura. Tradução Valério Rohden e Udo Baldur Moosburguer. 3. ed. São Paulo: Nova Cultural, 1987. V. 1 e 2. (Os Pensadores).

KUJAWSKI, Gilberto de Mello. A crise do século XX. São Paulo: Ática, 1991.

LEBRUN, Gérard. A filosofia e sua história. Organização: Carlos Alberto Ribeiro de Moura, Maria Lúcia M. O. Cacciola, Marta Kawano. São Paulo: Cosac Naify, 2006.

LYOTARD, Jean-François. 0 pós-moderno. Tradução. Ricardo Corrêa Barosa Rio de Janeiro: José Olympio, 1988.

MATOS, Olgária. Modernidade: o deslimite da razão e o esgotamento ético. In: NOVAES, Adauto (org.). Mutações: a experiência do pensamento. São Paulo: Edições Sesc SP, 2010.

McEWAN, Ian. Amor sem fim. Tradução de Jorio Dauster. São Paulo: Companhia das Letras, 2011.

NIETZSCHE, Friedrich. Sobre verdade e mentira em sentido extramoral. Tradução de Rubens Rodrigues Torres Filho São Paulo: Nova Cultural, 1987. (Os Pensadores). 
OLIVEIRA, Manfredo Araújo de. Reviravolta linguístico-pragmática na filosofia contemporânea. São Paulo: Loyola, 1996. p. 25-34.

PALMA, Alexandre. Educação física, corpo e saúde: uma reflexão sobre outros "modos de olhar". Revista Brasileira de Ciências do Esporte, v. 22, n. 2, p. 23-39, jan. 2001. Disponível em: http://www.rbceonline.org.br/revista/index.php/RBCE/article/view/410. Acesso em: 5 jul. 2013.

PALMER, Richard E. Hermenêutica. Tradução de Maria Luísa Ribeiro Ferreira Lisboa: Edições 70, [1997].

ROLIM, Marcos. A cultura do ódio. Zero Hora, Porto Alegre, p. 11, 29 jul. 2011.

ROSA, Guimarães. Grandes entrevistas. Guimarães Rosa 2. Entrevista conduzida por Günter Lorenz no Congresso de Escritores Latino-Americanos, em janeiro de 1965 e publicada em seu livro:

Diálogo com a América Latina. São Paulo: E.P.U., 1973. Disponível em:

http://www.tirodeletra.com.br/entrevistas/GuimaraesRosa-1965.htm. Acesso em: 17 ago. 2013.

ROSSI, Paolo. A ciência e a filosofia dos modernos: aspectos da Revolução Científica. Tradução de Álvaro Lorencini Rio Claro: Editora Unesp, 1992.

RUEDELL, Aloísio. Hermenêutica: da necessidade de interpretar para um modo de pensar. ljuí: Editora Unijuí, 2016.

SAVATER, Fernando. O valor de educar. Tradução de Monica Stahel. São Paulo: Martins Fontes, 1998.

SILVA, Ilton Benoni da. Inter-relação: a pedagogia da ciência: uma leitura do discurso epistemológico de Gaston Bachelard. Ijuí, RS: Editora Unijuí, 1999.

\section{SOBRE O AUTOR}

\section{Paulo Evaldo Fensterseifer}

Doutor em Educação pela Universidade Estadual de Campinas - SP (Unicamp); Professor do Departamento de Humanidades e Educação da Universidade Regional do Noroeste do Estado do Rio Grande do Sul (Unijuí). Brasil; Professor do Programa de Pós-graduação em Educação nas Ciências - Mestrado e Doutorado (PPGEC) e do Programa de Pós Graduação em Educação Física - Mestrado Profissional (PROEF). Grupo de Pesquisa: Paidotribas.

E-mail fenster@unijui.edu.br ORCID do autor: https://orcid.org/0000-0002-4914-5281 
